\title{
Implementasi Algoritma FP-Growth dengan Closure Table untuk Penemuan Frequent Itemset pada Keranjang Belanja
}

\author{
I Gusti Agung Indrawan ${ }^{1}$, Made Sudarma ${ }^{2}$, Lie Jasa ${ }^{3}$
}

\begin{abstract}
FP-growth algorithm is a data mining algorithm used to find frequent itemset in market basket data. Frequent itemset is a group of items that are often purchased together in one market basket. Analysis of frequent itemset will result in association rules. FP-growth algorithm finds frequent itemset by compressing market basket data into a tree structure called FPtree. FP-tree is then analyzed to extract frequent itemset. Market basket data is always increasing for every transaction that occurs, so the process of mining frequent itemset will re-create FP-tree from scratch repeatedly every time FP-growth algorithm executed. In order for FP-tree not to be re-created from the beginning every time FP-growth algorithm executed, FP-tree needs to be stored on storage media using format suitable for tree structure. This research stores FP-tree to table in database using closure table structure. The structure of closure table has several advantages that are suitable for storing tree structure. The results obtained from storing FP-tree to table in database using closure table structure is FP-tree that has been stored in database can be analyzed repeatedly without needing to be recreated from scratch, and only updated when market basket data increases.
\end{abstract}

Keywords- closure table, data mining, FP-growth, FP-tree, frequent itemset, market basket.

Intisari- Algoritma FP-growth adalah algoritma data mining yang digunakan untuk menemukan frequent itemset pada data keranjang belanja. Frequent itemset adalah kelompok barang yang sering dibeli bersamaan dalam satu keranjang belanja. Analisa frequent itemset menghasilkan aturan asosiasi. Algoritma FP-growth menemukan frequent itemset dengan mengkompresi data keranjang belanja ke struktur data tree yang disebut $F P$. tree. FP-tree kemudian dianalisa untuk mengekstrak frequent itemset. Data keranjang belanja selalu bertambah jumlahnya untuk setiap transaksi yang terjadi, sehingga proses penemuan frequent itemset akan membuat FP-tree dari awal secara berulang-ulang setiap kali algoritma FP-growth dijalankan. Agar $F P$-tree tidak perlu dibuat ulang dari awal setiap kali algoritma FP-growth dijalankan, maka FP-tree perlu disimpan pada media penyimpanan menggunakan format yang sesuai dengan struktur data tree. Penelitian ini menyimpan FP-tree ke tabel pada database dengan struktur closure table. Struktur closure table memiliki beberapa keunggulan sehingga cocok digunakan untuk menyimpan struktur data tree. Hasil yang didapatkan dari penyimpanan FP-tree ke tabel pada database menggunakan struktur closure table adalah FP-tree yang telah tersimpan pada database dapat dianalisa berulang kali tanpa perlu dibuat dari awal, dan hanya di-update ketika data keranjang belanja bertambah.

${ }^{1}$ Mahasiswa Magister Teknik Elektro, Universitas Udayana, Kampus Universitas Udayana Jl. P.B. Sudirman Denpasar Bali 80232 (tlp: 0361-239599; e-mail: agung.indrawan@gmail.com)

2, 3 Dosen Magister Teknik Elektro, Universitas Udayana, Kampus Universitas Udayana JL. P.B. Sudirman Denpasar Bali 80232 (tlp: 0361-239599; e-mail: ${ }^{2}$ msudarma@unud.ac.id, 3 liejasa@unud.ac.id)

I Gusti Agung Indrawan: implementasi algoritma fp-growth...
Kata Kunci- closure table, data mining, FP-growth, FP-tree, frequent itemset, keranjang belanja.

\section{PENDAHULUAN}

Usaha retail yang menggunakan sistem point-of-sales menyimpan data transaksi penjualan barang dalam jumlah besar. Data transaksi penjualan barang per pelanggan disebut data keranjang belanja. Data transaksi yang tersimpan dalam jumlah besar ini berpotensi memiliki knowledge yang belum diketahui. Sebagai contoh adalah knowledge tentang barang yang sering dibeli secara bersamaan dalam satu transaksi, yang dalam istilah data mining disebut frequent itemset. Knowledge tersebut dapat digunakan oleh retailer untuk meningkatkan penjualan, misal dengan membuat promosi bundel barang-barang tertentu dan meletakkan barang yang sering dibeli secara berdekatan pada rak penjualan. Penelitian untuk menemukan frequent itemset pada keranjang belanja sebelumnya dilakukan oleh [1].

Algoritma FP-growth menyimpan data keranjang belanja ke struktur data tree yang disebut FP-tree. Algorima FPgrowth yang dijabarkan oleh [2] dan [3] membangun dan menyimpan FP-tree pada random access memory (RAM). Kelemahan penyimpanan FP-tree pada RAM adalah FP-tree akan terhapus ketika program dihentikan atau komputer dimatikan. Solusi dari masalah tersebut adalah menyimpan FP-tree yang telah di-generate ke media penyimpanan data pada komputer. Struktur closure table adalah solusi yang elegan untuk menyimpan hierarki tree pada database. Closure table menyimpan seluruh path pada tree untuk node tertentu, tidak hanya node dengan relasi parent-child [4]. Keunggulan struktur closure table adalah query untuk menemukan seluruh child node untuk parent node tertentu hanya memerlukan satu kali query.

Penggunaan database untuk menyimpan FP-tree menggunakan struktur closure table diharapkan menghilangkan keterbatasan algoritma FP-growth dimana ukuran FP-tree dapat melebihi kapasitas memori utama yang tersedia pada komputer, terutama pada dataset keranjang belanja berukuran besar.

\section{STUDI LITERATUR}

\section{A. Data Mining}

Istilah data mining dapat dijelaskan sebagai proses menemukan pengetahuan (knowledge) atau pola (pattern) dari data berukuran besar [5]. Seiring dengan meningkatnya komputerisasi kegiatan masyarakat, kapasitas penyimpanan data yang semakin besar dan kemampuan processing komputer yang semakin cepat, mengakibatkan data yang dihasilkan dan disimpan oleh perorangan maupun organisasi tiap harinya sangatlah besar. Kegiatan sehari-hari seperti transaksi pembelian yang diproses dengan terminal point-ofp-ISSN:1693 - 2951; e-ISSN: 2503-2372

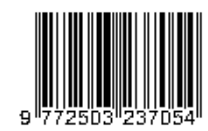


sales, penggunaan situs media sosial untuk melakukan sharing berita dan foto serta video, adalah contoh kegiatan yang menghasilkan data dalam jumlah besar.

Jumlah data yang sangat besar yang tidak dibarengi dengan wawasan (insight) yang cukup (knowledge) terhadap data tersebut disebut data rich but information poor. Hal ini diakibatkan tidak terpenuhinya kebutuhan terhadap alat analisis data yang handal. Situasi inilah yang kemudian memunculkan teknologi data mining.

\section{B. Aturan Asosiasi}

Frequent patterns adalah pola yang sering muncul pada dataset. Frequent patterns dapat berupa itemset, subsequences atau substructures. Kumpulan barang yang sering muncul bersamaan pada satu transaksi data, sebagai contoh susu dan roti yang sering dibeli bersamaan pada satu transaksi penjualan barang, disebut frequent itemset [6]. Penemuan frequent itemset pada data transaksi keranjang belanja memungkinkan perusahaan retail mengoptimalkan penjualan barang, misal dengan meletakkan barang-barang yang sering dibeli bersamaan pada rak yang berdekatan atau mengadakan promosi barang bundel.

Pada contoh sebelumnya, disebutkan susu dan roti sering dibeli bersamaan pada satu transaksi penjualan barang. Pola tersebut dapat dituliskan dalam bentuk aturan asosiasi seperti berikut:

$$
\{\text { Penghapus }\} \rightarrow\{\text { Pensil }\}
$$

Kekuatan aturan asosiasi dapat diukur menggunakan support dan confidence. Support menentukan seberapa sering aturan asosiasi $X \rightarrow Y$ berlaku pada suatu dataset [6]. Support dapat didefinisikan sebagai berikut:

$$
\text { Support, } s(X \rightarrow Y)=\frac{\sigma(X \cup Y)}{N}
$$

Confidence menentukan seberapa sering item $\mathrm{Y}$ muncul pada transaksi yang mengandung item X [6]. Confidence dapat didefinisikan sebagai berikut:

$$
\text { Confidence, } c(X \rightarrow Y)=\frac{\sigma(X \cup Y)}{\sigma(X)}
$$

\section{Algoritma FP-growth}

Algoritma FP-growth (FP: frequent-pattern) mengkodekan data menggunakan struktur data yang disebut FP-tree dan mengekstrak frequent itemset dari FP-tree tersebut. FP-tree adalah representasi terkompresi dari data keranjang belanja. FP-tree dibangun dengan membaca dataset transaksi per satu transaksi dan melakukan mapping item tiap transaksi tersebut ke sebuah path pada FP-tree [6]. Dikarenakan setiap transaksi berbeda dapat memiliki beberapa item transaksi yang sama, path item transaksi yang sama tersebut akan overlap pada path di FP-tree. Semakin banyak path yang overlap pada FPtree, semakin besar kompresi data yang bisa dicapai.

Penelitian sebelumnya tentang implementasi algoritma FPgrowth antara lain:

1. Referensi [7] membahas tentang optimasi algoritma FPgrowth yang dinamakan APFTC (Apriori with FP-tree and Correlation), dimana FP-tree mining untuk menemukan frequent itemset menggunakan algoritma apriori. Algoritma APFTC mengenalkan konsep korelasi untuk meningkatkan kualitas interestingness dari aturan asosiasi yang ditemukan.

2. Referensi [8] membahas tentang algoritma FP-growth yang dieksekusi menggunakan Apache Hadoop. Apache Hadoop adalah framework yang memungkinkan pemrosesan datasets berukuran besar secara paralel pada komputer terkluster. Penelitian ini menggunakan implementasi FP-growth dari Apache Mahout. Apache Mahout adalah library untuk mengembangkan aplikasi machine learning.

3. Referensi [9] membahas tentang optimasi algoritma FPgrowth yang dinamakan algoritma painting-growth dan $n$ painting-growth.

\section{Closure Table}

Struktur closure table menyimpan seluruh path pada tree untuk node tertentu, tidak hanya node dengan relasi parentchild [4]. Keunggulan struktur closure table adalah kemudahan melakukan query seluruh child node untuk parent node tertentu, sehingga cocok digunakan sebagai struktur tabel untuk menyimpan struktur data $F P$-tree yang digunakan algoritma FP-growth. Struktur closure table diimplementasikan sebagai tabel tambahan. Tabel tersebut bernama treepaths dan didefinisikan dengan SQL query sebagai berikut:

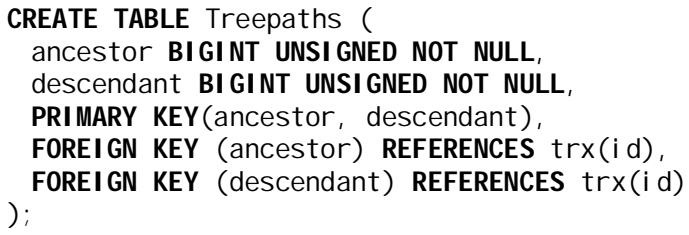

Tabel treepaths mereferensi kolom id yang merupakan primary key dari tabel trx (transaksi/market basket). Salah satu ciri struktur closure table adalah setiap node mereferensi dirinya sendiri. Setiap node juga menyimpan referensi/path ke semua child node yang ada dibawahnya. Tabel 1 menunjukkan data tabel nama barang, sedangkan tabel 2 menunjukkan data tabel treepaths.

Visualisasi data yang ada pada tabel 2 ditunjukkan di gambar 1. Garis biru menandakan referensi foreign keys untuk kolom ancestor dan descendant pada tabel treepaths. Garis hijau menandakan referensi foreign keys ke node itu sendiri.

Tabel 1: NAMA BARANG
\begin{tabular}{|c|c|}
\hline id & nama \\
\hline 1 & a \\
\hline 2 & b \\
\hline 3 & $\mathrm{c}$ \\
\hline 4 & $\mathrm{~d}$ \\
\hline 5 & $\mathrm{e}$ \\
\hline 6 & $\mathrm{f}$ \\
\hline 7 & $\mathrm{~g}$ \\
\hline
\end{tabular}


Tabel 2: DATA PADA TABEL TREEPATHS

\begin{tabular}{|c|c|}
\hline ancestor & descendant \\
\hline 1 & 1 \\
\hline 1 & 2 \\
\hline 1 & 3 \\
\hline 1 & 4 \\
\hline 1 & 5 \\
\hline 1 & 6 \\
\hline 1 & 7 \\
\hline 2 & 2 \\
\hline 2 & 3 \\
\hline
\end{tabular}

\begin{tabular}{|c|c|}
\hline ancestor & descendant \\
\hline 3 & 3 \\
\hline 4 & 4 \\
\hline 4 & 5 \\
\hline 4 & 6 \\
\hline 4 & 7 \\
\hline 5 & 5 \\
\hline 6 & 6 \\
\hline 6 & 7 \\
\hline 7 & 7 \\
\hline
\end{tabular}

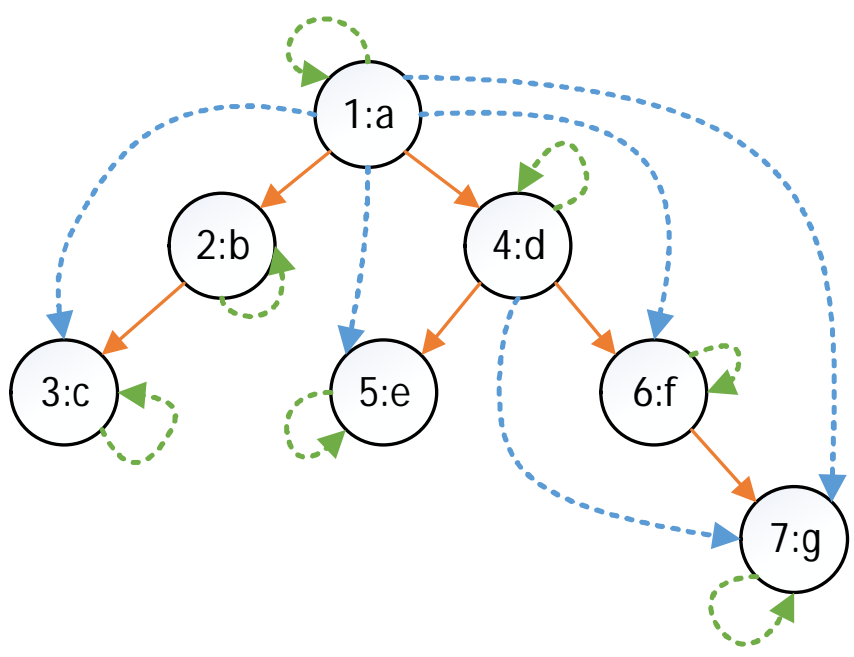

Gambar 1. Visualisasi Tree

III. METODE

A. Alur Implementasi Algoritma FP-growth Menggunakan Closure Table

Alur implementasi algoritma FP-growth dengan closure table dijelaskan sebagai berikut:

1. Data keranjang belanja yang berbentuk file teks ditransformasi agar dapat disimpan dalam bentuk tabel pada database.

2. Tentukan minimum support count untuk penemuan frequent itemset. Item yang tidak memenuhi minimum support count, dianggap infrequent dan tidak disertakan dalam proses mining. Update kolom is_min_sc pada tabel items dan tabel trx_details dengan nilai true/false sesuai dengan kondisi apakah frekuensi kemunculan barang pada dataset keranjang belanja memenuhi minimum support count atau tidak.

3. Scan tabel trx_detail untuk menentukan semua ID transaksi detail yang valid. ID transaksi detail dianggap valid ketika ID transaksi detail tersebut memiliki ID transaksi master dan frekuensi kemunculan barang pada transaksi detail tersebut pada dataset keranjang belanja memenuhi syarat minimum support count.

4. Scan tabel trx_detail untuk menemukan frekuensi kemunculan item pada keranjang belanja. Update jumlah frekuensi kemunculan item ke kolom freq pada tabel item.

5. Tahap berikutnya adalah pembuatan FP-tree. Item transaksi yang telah berurut secara descending, di-

I Gusti Agung Indrawan: implementasi algoritma fp-growth... mapping ke tabel treepaths yang disimpan pada DBMS MySQL menggunakan struktur closure table.

6. Setelah FP-tree terbentuk, tahap berikutnya adalah ekstraksi frequent itemset.

7. Frequent itemset yang telah ditemukan, digunakan untuk membuat aturan asosiasi. Aturan asosiasi kemudian ditampilkan dalam bentuk laporan, beserta perhitungan support dan confidence aturan asosiasi tersebut.

\section{B. Struktur Tabel di Database}

Struktur data FP-tree yang dihasilkan oleh algoritma FPgrowth disimpan sebagai closure table pada database MySQL. Tabel yang menyimpan FP-tree pada database MySQL dinamakan tabel treepaths dan didefinsikan dengan SQL query sebagai berikut:

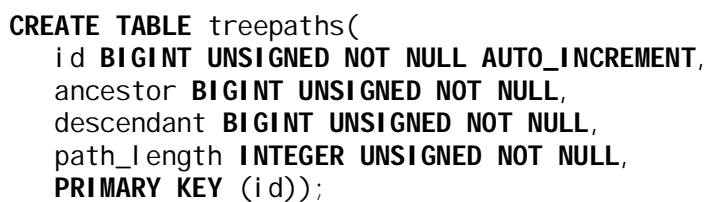

\section{ALTER TABLE treepaths ADD CONSTRAINT}

fk treepaths anc ref items id FOREIGN KEY (ancestor) REFERENCES items (id_item) ;

\section{ALTER TABLE treepaths ADD CONSTRAINT}

fk_treepaths des_ref_items_id FOREIGN KEY (descendant) REFERENCES items (id_item);

Struktur tabel treepaths dapat dilihat pada tabel 3. Kolom id menyimpan identity dari tiap node, yaitu angka bulat (integer) yang membedakan tiap node. Kolom ancestor menyimpan id node yang merupakan ancestor dari node saat ini, dan kolom descendant menyimpan id node yang merupakan descendant dari node saat ini. Kolom path_length menyimpan jarak node antara node ancestor dan descendant.

\section{Tabel 3: STRUKTUR TABEL TREEPATHS}

\begin{tabular}{|c|l|l|l|}
\hline No & Nama Kolom & \multicolumn{1}{|c|}{ Tipe Data } & \multicolumn{1}{|c|}{ Key } \\
\hline 1 & id & Big Integer Unsigned & PK, NN, AI \\
\hline 2 & ancestor & Big Integer Unsigned & NN, FK \\
\hline 3 & descendant & Big Integer Unsigned & NN, FK \\
\hline 4 & path_length & Integer Unsigned & NN \\
\hline
\end{tabular}

Selain tabel treepaths, terdapat tabel lain yang digunakan untuk menyimpan data transaksi penjualan barang. Nama dan struktur data tabel tersebut dapat dilihat pada tabel 4, 5, 6 dan

Tabel 4: STRUKTUR TABEL TRX_MASTER

\begin{tabular}{|c|c|c|c|}
\hline No & Nama Kolom & Tipe Data & Key \\
\hline 1 & tid & Big Integer Unsigned & PK \\
\hline
\end{tabular}

Tabel 5: STRUKTUR TABEL TRX_DETAILS

\begin{tabular}{|c|l|l|l|}
\hline No & Nama Kolom & \multicolumn{1}{|c|}{ Tipe Data } & Key \\
\hline 1 & tid_detail & Big Integer Unsigned & PK \\
\hline 2 & tid & Big Integer Unsigned & FK \\
\hline 3 & id_item & Big Integer Unsigned & FK \\
\hline 4 & is_min_sc & Boolean & - \\
\hline
\end{tabular}

p-ISSN:1693 - 2951; e-ISSN: 2503-2372 
Tabel 6: STRUKTUR TABEL ITEMS

\begin{tabular}{|c|l|l|l|}
\hline No & Nama Kolom & \multicolumn{1}{|c|}{ Tipe Data } & Key \\
\hline 1 & id_item & Big Integer Unsigned & PK \\
\hline 2 & freq & Integer Unsigned & NN \\
\hline 3 & is_min_sc & Boolean & - \\
\hline
\end{tabular}

Tabel 7: Struktur Tabel items_name

\begin{tabular}{|c|l|l|l|}
\hline No & Nama Kolom & \multicolumn{1}{|c|}{ Tipe Data } & Key \\
\hline 1 & id_item & Integer & PK \\
\hline 2 & Name & Varchar(255) & NN \\
\hline
\end{tabular}

C. Penyimpanan FP-tree ke Closure Table

Algoritma penyimpanan FP-tree ke closure table dijelaskan sebagai berikut:

1. Langkah pertama adalah meng-insert root node FP-tree ke tabel treepaths. Pada algoritma FP-growth, root node dari FP-tree adalah node dengan data null, dan pada algoritma ini diimplementasikan dengan angka nol sebagai nilai kolom ancestor dan descendant. Kolom path_length berisi nilai nol karena baris data ini adalah node pertama.

2. Item pada keranjang belanja yang memenuhi syarat minimum support count, diurutkan secara descending berdasarkan jumlah kemunculan item tersebut pada dataset keranjang belanja.

3. Item keranjang belanja yang sudah terurut, di-insert ke tabel treepaths berdasarkan pseudo code sebagai berikut:

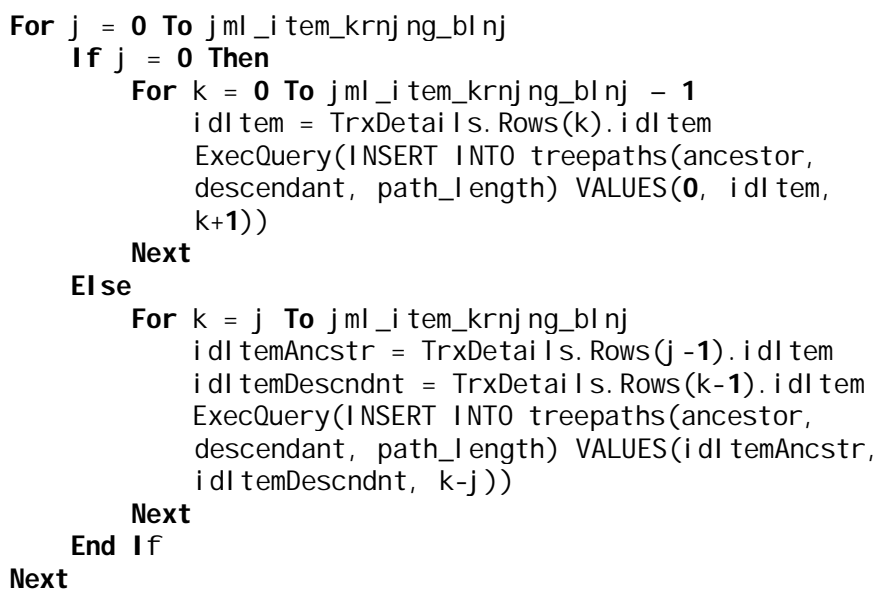

\section{Ekstraksi Frequent Itemset Dari Closure Table}

Algoritma ekstraksi frequent itemset dari tabel treepaths dijelaskan sebagai berikut:

1. Scan tabel items untuk menemukan item yang memenuhi kriteria minimum support count. Untuk semua item yang memenuhi kriteria tersebut, dapatkan ancestor-nya menggunakan SQL query sebagai berikut:

Select ancestor FROM treepaths

WHERE descendant $=$ idItem

2. Hasil dari query tersebut adalah multiple paths dimana tiap path berisi item yang dibeli bersamaan dengan item yang sedang diproses. Tiap path pada multiple paths dipisahkan dengan data ancestor $=0$ (nol).

3. Langkah ketiga adalah memecah multiple paths menjadi path individual. Pemecahan multiple paths kemungkinan menghasilkan path duplikat yang memiliki urutan/sequence id item yang sama. Jumlah kemunculan path duplikat yang memiliki urutan/sequence id item yang sama tersebut disimpan sebagai support count path tersebut. Path yang duplikat kemudian dihapus sehingga tersisa satu path individual yang memiliki support count yang bersesuaian.

4. Langkah keempat adalah menemukan semua id item unik yang disimpan sebagai end node di path individual. Semua id item unik yang ditemukan disimpan dalam list.

5. Langkah kelima adalah melakukan iterasi untuk semua id item unik yang ada pada list, temukan path individual yang memiliki end node sama dengan id item tersebut. Tambahkan support count semua path individual yang memiliki end node sama dengan id item, sebagai support count id item tersebut. Tentukan juga support count untuk node lain pada path individual dengan end node sama dengan id item yang sedang diproses.

6. Bila support count id item $\geq$ minimum support count, maka id item tersebut frequent. Pada titik ini penemuan frequent 1-itemset sudah selesai.

7. Langkah ketujuh adalah penemuan frequent 2-itemset. Pada tahap 5, support count untuk node lain pada path individual dengan end node sama dengan id item yang sedang diproses sudah dihitung. Bila support count node lain tersebut $\geq$ minimum support count, maka node lain tersebut adalah frequent dan anggota frequent 2-itemset dari id item yang sedang diproses.

\section{HASIL DAN PEMBAHASAN}

Pembahasan implementasi algoritma FP-growth menggunakan closure table untuk penemuan frequent itemset menggunakan contoh data keranjang belanja alat tulis yang dapat dilihat pada tabel 8 dan tabel 9 .

Tabel 8: Tabel item_name Alat Tulis

\begin{tabular}{|c|l|}
\hline id_item & \multicolumn{1}{|c|}{ nama } \\
\hline 1 & Pensil \\
\hline 2 & Bolpoin \\
\hline 3 & Buku Tulis \\
\hline 4 & Penghapus \\
\hline 5 & Rautan \\
\hline 6 & Penggaris \\
\hline 7 & Kertas \\
\hline
\end{tabular}

Tabel 9: Data Keranjang Belanja Alat Tulis

\begin{tabular}{|c|l|}
\hline tid & id_item \\
\hline 1 & 231 \\
\hline 2 & 23 \\
\hline 3 & 3145 \\
\hline 4 & 716 \\
\hline 5 & 2146 \\
\hline 6 & 154 \\
\hline
\end{tabular}

Tampilan program implementasi algoritma FP-growth dengan closure table yang diberi nama FP-miner dapat dilihat pada gambar 2 . 


\begin{tabular}{|c|c|c|c|}
\hline \multicolumn{2}{|c|}{} & 203 \\
\hline 53 & 1 & 5 & 2 \\
\hline 54 & 4 & 4 & 0 \\
\hline 55 & 4 & 5 & 1 \\
\hline 56 & 5 & 5 & 0 \\
\hline
\end{tabular}

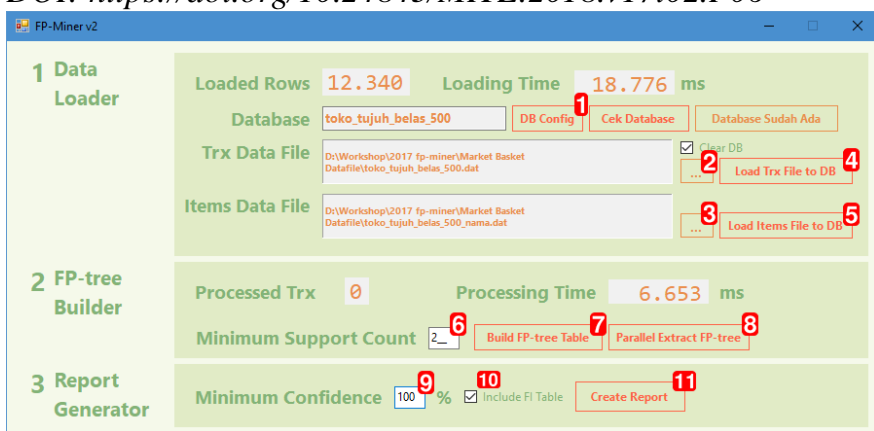

Gambar 2. Tampilan Program FP-miner

Tahapan penggunaan program FP-miner dijelaskan sebagai berikut:

1. Langkah pertama adalah melakukan konfigurasi koneksi database MySQL.

2. Langkah kedua adalah melakukan transformasi data dari data keranjang belanja yang berupa file teks menjadi record pada database. Langkah transformasi data ini dilakukan di bagian (1 Data Loader) pada program FPminer.

3. Langkah ketiga adalah membuat FP-tree yang akan disimpan pada tabel treepaths pada database MySQL. Langkah pembuatan FP-tree ini dilakukan di bagian (2 FP-tree Builder) pada program FP-miner. Penentuan minimum support count dilakukan pada langkah ini. FPtree yang dihasilkan berdasarkan data keranjang belanja alat tulis pada tabel 9 disimpan pada tabel treepaths dan ditunjukkan pada tabel 10 .

4. Langkah keempat adalah melakukan ekstraksi frequent itemset dari tabel treepaths. Langkah ini dilakukan dengan mengklik tombol (Extract FP-tree).

5. Langkah kelima adalah pembuatan laporan aturan asosiasi. Pembuatan laporan ini dilakukan dibagian (3 Report Generator) pada program FP-miner. Penentuan minimum confidence aturan asosiasi yang akan dilaporkan ditentukan pada tahap ini. Bila minimum confidence dikosongkan, maka program akan melaporkan semua aturan asosiasi yang ditemukan. Opsi (Include FI Table) bila dicentang maka pada laporan aturan asosiasi akan ditampilkan data frequent itemset yang ditemukan saat proses ekstraksi frequent itemset dari FP-tree. Tabel 11 menunjukkan frequent itemset untuk data keranjang belanja alat tulis.

Tabel 10: Tabel Treepaths Alat Tulis

\begin{tabular}{|c|c|c|c|}
\hline id & ancestor & descendant & path_length \\
\hline 1 & 0 & 1 & 1 \\
\hline 2 & 0 & 2 & 2 \\
\hline 3 & 0 & 3 & 3 \\
\hline 4 & 1 & 1 & 0 \\
\hline 5 & 1 & 2 & 1 \\
\hline 6 & 1 & 3 & 2 \\
\hline 7 & 2 & 2 & 0 \\
\hline 8 & 2 & 3 & 1 \\
\hline 9 & 3 & 3 & 0 \\
\hline$\ldots$ & $\ldots$ & $\ldots$ & $\ldots$ \\
\hline 52 & 1 & 4 & 1 \\
\hline
\end{tabular}

I Gusti Agung Indrawan: implementasi algoritma fp-growth...
Tabel 11: Frequent Itemset Keranjang Belanja Alat Tulis

\begin{tabular}{|c|c|}
\hline Suffix & Frequent Itemset \\
\hline Penggaris & $\begin{array}{l}\text { \{Penggaris:2 }\} \\
\{\text { Pensil,Penggaris:2 }\}\end{array}$ \\
\hline Rautan & $\begin{array}{l}\{\text { Rautan:2 }\} \\
\text { \{Penghapus,Rautan:2\} } \\
\text { \{Pensil,Rautan:2\} } \\
\text { \{Pensil,Penghapus,Rautan:2\} }\end{array}$ \\
\hline Penghapus & $\begin{array}{l}\{\text { Penghapus: } 3\} \\
\{\text { Pensil,Penghapus:3\} }\end{array}$ \\
\hline $\begin{array}{l}\text { Buku } \\
\text { Tulis }\end{array}$ & $\begin{array}{l}\{\text { Buku Tulis:3\} } \\
\{\text { Bolpoin,Buku Tulis:2\} } \\
\{\text { Pensil,Buku Tulis:2 }\}\end{array}$ \\
\hline Bolpoin & $\begin{array}{l}\text { \{Bolpoin:3\} } \\
\{\text { Pensil,Bolpoin:2\} }\end{array}$ \\
\hline Pensil & $\{$ Pensil:5\} \\
\hline
\end{tabular}

6. Laporan aturan asosiasi yang ditemukan disimpan dalam format file html pada folder yang sama dengan folder dimana program FP-miner dijalankan. Laporan aturan asosiasi yang ditemukan pada data keranjang belanja alat tulis adalah sebagai berikut:

1. $\{$ Penggaris $\rightarrow$ Pensil $\}$
a. Support $=2 / 6=33,33 \%$
b. Confidence $=2 / 2=100 \%$

2. $\{$ Rautan $\rightarrow$ Penghapus $\}$

a. Support $=2 / 6=33,33 \%$

b. Confidence $=2 / 2=100 \%$

3. $\{$ Rautan $\rightarrow$ Pensil $\}$

a. Support $=2 / 6=33,33 \%$

b. Confidence $=2 / 2=100 \%$

4. $\{$ Rautan,Penghapus $\rightarrow$ Pensil $\}$

a. Support $=2 / 6=33,33 \%$

b. Confidence $=2 / 2=100 \%$

5. $\{$ Penghapus $\rightarrow$ Pensil $\}$

a. Support $=3 / 6=50 \%$

b. Confidence $=3 / 3=100 \%$

\section{KESIMPULAN}

Kesimpulan yang bisa didapatkan dari implementasi algoritma FP-growth menggunakan closure table adalah struktur data FP-tree yang digunakan oleh algoritma FPgrowth sebagai representasi terkompresi data keranjang belanja, dapat disimpan sebagai tabel di-database menggunakan struktur closure table. Penambahan data keranjang belanja baru tidak mengakibatkan pembuatan ulang FP-tree dari awal, cukup data keranjang belanja baru saja yang disimpan ke tabel treepaths sehingga mempercepat proses penemuan frequent itemset secara keseluruhan.

\section{REFERENSI}

p-ISSN:1693 - 2951; e-ISSN: 2503-2372 
[1] A. W. O. Gama, I. K. G. D. Putra, I. P. A. Bayupati, "Implementasi Algoritma Apriori untuk Menemukan Frequent Itemset Dalam Keranjang Belanja", Majalah Ilmiah Teknologi Elektro, vol.15, JuliDesember 2016.

[2] R. Agrawal, et al, Mining Association Rules between Sets of Items in Large Databases. Proceedings of the 1993 ACM SIGMOD Conference Washington DC, USA. 1993.

[3] R. Agrawal and R. Srikant, Fast Algorithm for Mining Association Rules. Proceeding of the 20th VLDB Conference Santiago, Chile. 1994.

[4] B. Karwin, SQL Antipatterns: Avoiding the Pitfalls of Database Programming 1st Edition, Texas: The Pragmatic Bookshelf, 2010.

[5] J. Han and M. Kamber, Data Mining Concept and Techniques, 3rd edition, USA: Elsevier, Inc, 2012.

[6] P. N. Tan, et al, Introduction to Data Mining, USA: Addison-Wesley, 2005.

[7] S. Dandu, "Improved Algorithm for Frequent Item sets Mining Based on Apriori and FP-Tree", Global Journal of Computer Science and Technology., vol. 13, no 2-C, 2013.

[8] R. An, J. Pan, "Association Analysis of Large Sample Data Based on Hadoop", in Proc. 2015 International Industrial Informatics and Computer Engineering Conference, 2015.

[9] Y. Zeng, S. Yin, J. Liu, and M. Zhang, "Research of Improved FPGrowth Algorithm in Association Rules Mining", Scientific Programming., 2015. 